\title{
Possible Mosquito Control by Silver Nanoparticles Synthesized by Soil Fungus (Aspergillus niger 2587)
}

\author{
Namita Soni, Soam Prakash* \\ Environmental and Advanced Parasitology and Vector Control Biotechnology Laboratory, Department of Zoology, \\ Faculty of Science, Dayalbagh Educational Institute, Dayalbagh, India \\ Email: "prakashsoamdei@gmail.com
}

Received December 14, 2012; revised January 15, 2013; accepted January 22, 2013

Copyright (c) 2013 Namita Soni, Soam Prakash. This is an open access article distributed under the Creative Commons Attribution License, which permits unrestricted use, distribution, and reproduction in any medium, provided the original work is properly cited.

\begin{abstract}
Here, we have synthesized the silver nanoparticles (AgNPs) by using the soil fungus Aspergillus niger 2587. The results recorded from UV-vis spectrophotometer and transmission electron microscopy (TEM) support the biosynthesis and characterization of AgNPs. The synthesized silver nanoparticles have also been tested against the larvae and pupae of Anopheles stephensi, Culex quinquefasciatus and Aedes aegypti. The efficacy test was performed at different concentrations for a period of different hours by the probit analysis. The larvae of $C x$. quinquefasciatus have shown the $100 \%$ mortality to the synthesized AgNPs after $1 \mathrm{~h}$ of exposure, while the larvae of An. stephensi and Ae. aegypti were found less susceptible to the synthesized AgNPs. The pupa of Ae. aegypti has shown the efficacy LC $\mathrm{L}_{50} 4, \mathrm{LC}_{90} 12$ and LC $_{99} 19$ ppm after $2 \mathrm{~h}$ of exposure of the synthesized AgNPs, while, the pupae of Cx. quinquefasciatus and An. stephensi were found less susceptible to the synthesized AgNPs. By this approach, it is suggestive that this rapid synthesis of nanoparticles would be proper for developing a biological process for mosquito control.
\end{abstract}

Keywords: Soil Fungus; Silver Nanoparticles; Mosquito Control

\section{Introduction}

Mosquito vectors are solely responsible for transmitting diseases such as malaria, dengue, chikungunya, Japanese encephalitis, and lymphatic filariasis. Anopheles species are the most important species as they are capable vector for malaria parasites. About 3.3 billion people-half of the world's population-are at risk of malaria. In 2010, there were about 216 million malaria cases (with an uncertainty range of 149 million to 274 million) and an estimated 655,000 malaria deaths (with an uncertainty range of 537,000 to 907,000 ). Increased prevention and control measures have led to a reduction in malaria mortality rates by more than 25\% globally since 2000 and by $33 \%$ in the WHO African Region [1].

Culex mosquitoes are painful and persistent biters and are responsible for filariasis. Lymphatic filariasis is a neglected tropical disease. More than 1.3 billion people in 72 countries worldwide are threatened by lymphatic filariasis, commonly known as elephantiasis. Over 120 million people are currently infected, with about 40 million disfigured and incapacitated by the disease [2].

Aedes mosquitoes on the other hand are also painful

"Corresponding author. and persistent biters. Ae. aegypti is responsible for spreading dengue. The incidence of dengue has grown dramatically around the world in recent decades. Over 2.5 billion people-over $40 \%$ of the world's population-are now at risk from dengue. WHO currently estimates there may be 50 - 100 million dengue infections worldwide every year [3]?

The problem has a complex face and it has to be handled carefully. It is essential to control mosquito population so that people can be protected from mosquito borne diseases. These diseases can be controlled by targeting the causative parasites and pathogens. It is easier to control vectors than parasites. The chemical control was one of the most widely used conventional methods for mosquito control since chemical pesticides are relatively inexpensive usually produces immediate control. Generally, the chemical control is carried out by the indoor residual spraying of insecticides such as dichloro diphenyl trichloro ethane, hexa chlorocyclo hexane, benzene hexa chloride, melathion and synthetic pyrothroid. But, the development of resistance against these chemicals in various mosquito populations has been reported.

It is known that larvicides play a vital role in control- 
ling mosquitoes in their breeding sites. Two insecticidal bacteria have been used as larvicides to control larvae of nuisance and vector mosquitoes in many countries, Bascillus thuringienesis ssp. Israelensis and Bascillus sphaericus [4]. Field studies have shown that both are effective, but serious resistance, as high as 50,000 fold, has evolved where $B$. sphaericus is used against Culex mosquitoes. Unfortunately, the development of resistance against the larvicide in various mosquito populations has also been reported.

Therefore, biological control can thus provide and effective and environmental friendly approach, which can be used as an alternative to minimize the mosquito population. Fungi and fungus derived products are highly toxic to mosquitoes, yet have low toxicity to non-target organisms [5]. The secondary metabolites of entomopathogenic fungi Chrysosporium [6], Fusarium [7], Aspergillus [8], and Verticillium [9] have been screened successfully as a potential larvicide.

Fungi are also been used in nanotechnology for producing nanoparticles. Therefore, present green synthesis has shown that the environmentally benign and renewable source of fungi used as an effective reducing agent for the synthesis of silver nanoparticles. Biosynthesis of silver nanoparticles (AgNPs) by using a fungus Trichoderma [10,11], Aspergillus [12,13], and Fusarium [14,15] have been reported.

The larvicidal activities of mycosynthesized silver nanoparticles against vectors: Ae. aegypti and An. stephensi responsible for diseases of public health importance have been evaluated [16]. The silver and gold nanoparticles synthesized with $C$. tropicum have been tested as a larvicide against the mosquito larvae $[17,18]$. The silver nanoparticles synthesized by using the fungi have also been tested against adult mosquito [19].

The present communication describes the larvicidal and pupicidal effect of extracellular synthesized silver nanoparticles by using the soil fungi $A$. niger 2587 against the An. stephensi, Ae. aegypti and $C x$. quinquefasciatus mosquitoes. A. niger is filamentous keratinophilic fungi with compact white or yellow basal felt covered by a dense layer of dark-brown to black conidial heads. This fungus secret some reducing agents which convert silver nitrate into silver nanoparticles. Therefore, it can be a useful green exercise to invent and discover new fungal nanolarvicide for respective ecology and environmental management system.

\section{Experimental}

\subsection{Fungal Strain, Preparation of Broth and Culture of $A$. niger}

The fungal strain of A. niger (MTCC 2587) was obtained from the Microbial Type Culture Collection and Gene
Bank, Institute of Microbial Technology, Chandigarh, India, and was routinely maintained in the laboratory on Czapek-Dox Agar (CDA) at $25^{\circ} \mathrm{C}$.

The broth was prepared for culture of $A$. niger following the method [20]. Five $250 \mathrm{ml}$ conical flasks, each containing $100 \mathrm{ml}$ of Czapek-Dox Broth (sucrose $30 \mathrm{~g}$, sodium nitrate $3 \mathrm{~g}$, dipotassium phosphate $1 \mathrm{~g}$, magnesium sulphate $0.05 \mathrm{~g}$, potassium chloride $0.05 \mathrm{~g}$, ferrous sulphate $0.01 \mathrm{~g}$, and deionized water $1000 \mathrm{~mL}$ ), were autoclaved at 20 psi for 20 minutes. The broth was supplemented with chloramphenicol $(50 \mu \mathrm{g} / \mathrm{mL})$ as a bacteriostatic agent. $A$. niger colonies grown on CDA plates were transferred to each flask by inoculation needle. The conical flasks inoculated with $A$. niger were incubated at $25^{\circ} \mathrm{C}$ for 15 days.

\subsection{Synthesis and Characterization of AgNPs}

The fungal colonies of $A$. niger was grown on CDA. After 7 days incubation of fungal colonies on CDA plates were further transferred CDB containing conical flask by inoculation needle. The conical flasks inoculated with $A$. niger were incubated at $25^{\circ} \mathrm{C}$ for 15 days. After 15 days incubation the fungal biomass was separated from the medium by filtration through whatman-1 filter paper. The biomass was washed thrice in sterile distilled water to remove any nutrient media that might interact with silver ions. Approximately $10 \mathrm{~g}$ of fungal wet biomass of fungus was transferred to $250 \mathrm{ml}$ conical flask containing $100 \mathrm{ml}$ of distilled water and incubated for $72 \mathrm{~h}$ at $25^{\circ} \mathrm{C}$. After then the aqueous solution component was separated by filtration using whatman-1 filter paper. To this solution (aqueous solution component of $A$. niger), $\mathrm{AgNO}_{3}$ $\left(10^{3} \mathrm{M}\right)$ solution was added and kept for $72 \mathrm{~h}$ at $25^{\circ} \mathrm{C}$ in BOD incubator. Simultaneously, the control without adding $\mathrm{AgNO}_{3}$ was maintained under the same conditions, separately. The protein, enzyme and other compound present in the fungal liquid work as reducing agents and are responsible for conversion of silver nitrate to silver nanoparticles. The reaction may be written as $A$. niger (fungal liquid) +

Silver nitrate solution $\frac{\text { Enzyme/protein }}{\text { reducing agent }}$ Silver nanoparticles. Periodically, aliquot of the reaction solution was removed and their absorption was measured in UV-vis spectrophotometer. The micrograph of AgNPs was obtained by Philips CM-10 Transmission Electron Microscope.

\subsection{Bioassays and Statistical Analysis}

The larvicidal and pupicidal activity of synthesized AgNPs against the $C x$. quinquefasciatus, Ae. aegypti and An. stephensi was assessed by using the standard method [21]. Bioassays were conducted separately at six different 
test concentrations $(2,4,6,8,10$, and $12 \mathrm{ppm})$ of aqueous AgNPs. To test the larvicidal and pupicidal activity of synthesized AgNPs, 20 larvae and pupae of $C x$. quinquefasciatus, Ae. aegypti and An. stephensi were separately exposed to $100 \mathrm{ml}$ of test concentrations. Similarly, the control (without AgNPs) was run to test the natural mortality. Thereafter, we could further examine the mortality which was determined after different hours of treatment, the experiment time. No food was offered to the larvae during the experiment. Experiments were replicated thrice to validate the results. The data on the efficacy was subjected to probit analysis [22]. The control mortality was corrected by Abbott's formula [23].

\section{Results}

\subsection{UV-Vis Spectrophotometer and TEM Analysis of Synthesized AgNPs}

By mixing the fungal liquid component of $A$. niger with the aqueous solution of Ag ions, the colour of fungal liquid changed from white to dark brown colour after $72 \mathrm{~h}$ of incubation. The change in colour is a signal for the formation of AgNPs. Figure 1(a) shows the UV-vis spectra of AgNPs synthesized by using the $A$. niger recorded from the reaction medium before (1) and after immersion of $\mathrm{AgNO}_{3}$ (2) after 72 h. Absorption spectra of AgNPs formed in the reaction medium has a broad absorption band centred at ca. $480 \mathrm{~nm}$. The presence of broad resonance indicated an aggregated structure of the AgNPs in the solution.

Figure 1(b) shows the TEM micrograph of $A$. niger synthesized AgNPs. The 20 - $70 \mathrm{~nm}$ sized and spherical shaped AgNPs were observed.

\subsection{Efficacy Study of Synthesized AgNPs by Using the $A$. niger against the Larvae and Pupae of Cx. quinquefasciatus, Ae. aegypti and An. stephensi}

The A. niger synthesized AgNPs were found effective against the larvae and pupae of $C x$. quinquefasciatus, Ae. aegypti and An. stephensi. The larvaes of $C x$. quinquefasciatus, Ae. aegypti and An. stephensi were found highly susceptible to the synthesized AgNPs than the pupae at the same test concentrations. The mortality could be observed after different hours of exposure.

The larvae of $C x$. quinquefasciatus were found highly susceptible to the synthesized AgNPs than the larvae of Ae. aegypti and An. stephensi. The mortality was scored after $1 \mathrm{~h}$. The early three instars of $C x$. quinquefasciatus were found more susceptible to the synthesized AgNPs and shown the $100 \%$ mortality after $1 \mathrm{~h}$ of exposure. While, the fourth instar larvae were less susceptible to the synthesized AgNPs.

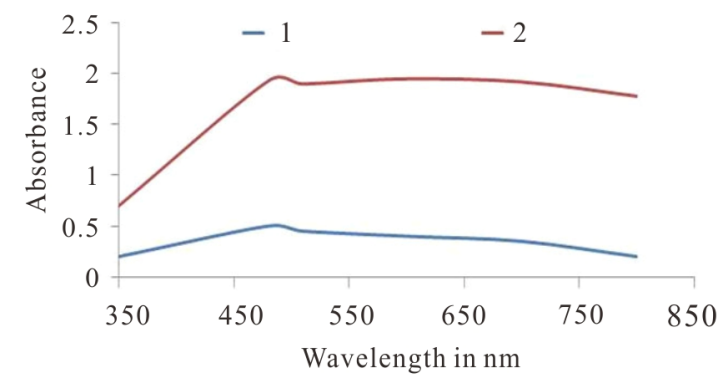

(a)

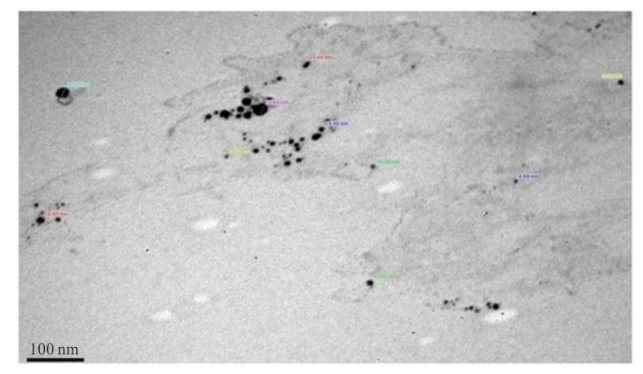

(b)

Figure 1. (a) UV-vis spectra of synthesized AgNPs from fungal liquid of $A$. niger before (1) and after immersion in $10^{-3} \mathrm{M}$ aqueous $\mathrm{AgNO}_{3}$ solution for $72 \mathrm{~h}$ (2); (b) TEM image of $A$. niger synthesized AgNPs.

The third instar larvae of Ae. aegypti were found highly susceptible to the synthesized AgNPs and shown the $100 \%$ mortality after $1 \mathrm{~h}$. However, the first and fourth instar larvae were less effective to the synthesized AgNPs and no adverse effects could be observed in the second instar larvae after same hour of exposure. The efficacy for first instars $\left(\mathrm{LC}_{50} 5.62, \mathrm{LC}_{90}\right.$ 12.50, $\mathrm{LC}_{99}$ $13.48 \mathrm{ppm}$ ) and for fourth instars ( $\mathrm{LC}_{50} 4.67, \mathrm{LC}_{90} 8$, $\mathrm{LC}_{99} 12.58 \mathrm{ppm}$ ) were recorded with their probit equations and confidential limits (Table 1). The chi-square values calculated at $4 \mathrm{df}$ were 39.17 and 48.80 for first and fourth instars. These chi-square values for first and fourth instars were found higher than the critical value of chi-square at 0.05 significance level. The relationship between the concentrations and \% mortality were shown for each of larval stage of Ae. aegypti (Figure 2).

The AgNPs synthesized by using the A. niger were found effective against the larval stages of An. stephensi. The mortality was observed after $24 \mathrm{~h}$ of exposure. The first and second instar larvae of An. stephensi have shown $100 \%$ mortality after $24 \mathrm{~h}$. While, the efficacy for third instars ( $\left.\mathrm{LC}_{50} 1.58, \mathrm{LC}_{90} 8.91, \mathrm{LC}_{99} 12.30 \mathrm{ppm}\right)$ and for fourth instars ( $\mathrm{LC}_{50} 2, \mathrm{LC}_{90} 12, \mathrm{LC}_{99} 13.18 \mathrm{ppm}$ ) were calculated with their probit equations and confidential limits (Table 1). The chi-square values calculated at $4 \mathrm{df}$ were 56.10 and 46.70 for third and fourth instars. These chi-square values for third and fourth instars were higher than the critical value of chi-square at 0.05 significance level. The relationship between the concentrations and \% mortality were shown for each of larval 
Table 1. Larvicidal efficacies of AgNPs synthesized by using the A. niger against the Cx. quinquefasciatus, Ae. aegypti and An. stephensi.

\begin{tabular}{|c|c|c|c|c|c|c|c|c|c|}
\hline Species & Instar & $\begin{array}{l}\text { Exposure } \\
\text { time (hrs) }\end{array}$ & $\begin{array}{c}\text { Concentrations } \\
\text { (ppm) }\end{array}$ & $\begin{array}{c}\% \\
\text { mortality }\end{array}$ & $\begin{array}{c}\text { Probit } \\
\text { equations }\end{array}$ & $\mathrm{LC}_{50}$ & $\mathrm{LC}_{90}$ & $\mathrm{LC}_{99}$ & $x^{2}$ \\
\hline \multirow[t]{24}{*}{$\begin{array}{c}C x . \\
\text { quinquefasciatus }\end{array}$} & $1 \mathrm{st}$ & 1 & 2 & 100 & $\mathrm{a}$ & a & a & $\mathrm{a}$ & a \\
\hline & & & 4 & 100 & & & & & \\
\hline & & & 6 & 100 & & & & & \\
\hline & & & 8 & 100 & & & & & \\
\hline & & & 10 & 100 & & & & & \\
\hline & & & 12 & 100 & & & & & \\
\hline & 2nd & 1 & 2 & 10 & a & $\mathrm{a}$ & a & a & a \\
\hline & & & 4 & 50 & & & & & \\
\hline & & & 6 & 65 & & & & & \\
\hline & & & 8 & 90 & & & & & \\
\hline & & & 10 & 95 & & & & & \\
\hline & & & 12 & 100 & & & & & \\
\hline & 3rd & 1 & 2 & 60 & a & a & a & a & a \\
\hline & & & 4 & 70 & & & & & \\
\hline & & & 6 & 80 & & & & & \\
\hline & & & 8 & 90 & & & & & \\
\hline & & & 10 & 100 & & & & & \\
\hline & & & 12 & 100 & & & & & \\
\hline & 3rd & 1 & 2 & 00 & b & b & b & b & b \\
\hline & & & 4 & 00 & & & & & \\
\hline & & & 6 & 00 & & & & & \\
\hline & & & 8 & 00 & & & & & \\
\hline & & & 10 & 00 & & & & & \\
\hline & & & 12 & 00 & & & & & \\
\hline \multirow[t]{24}{*}{ Ae. aegypti } & $1 \mathrm{st}$ & 1 & 2 & 20 & $\begin{array}{c}y= \\
0.4+6.12 x\end{array}$ & $\begin{array}{c}5.62 \\
(4.53-6.71)\end{array}$ & $\begin{array}{c}12.50 \\
(11.38-13.62)\end{array}$ & $\begin{array}{c}13.48 \\
(12.36-14.6)\end{array}$ & 39.17 \\
\hline & & & 4 & 45 & & & & & \\
\hline & & & 6 & 55 & & & & & \\
\hline & & & 8 & 65 & & & & & \\
\hline & & & 10 & 70 & & & & & \\
\hline & & & 12 & 75 & & & & & \\
\hline & 2nd & 1 & 2 & 00 & b & b & b & b & b \\
\hline & & & 4 & 00 & & & & & \\
\hline & & & 6 & 00 & & & & & \\
\hline & & & 8 & 00 & & & & & \\
\hline & & & 10 & 00 & & & & & \\
\hline & & & 12 & 00 & & & & & \\
\hline & 3rd & 1 & 2 & 60 & $\mathrm{a}$ & a & a & a & a \\
\hline & & & 4 & 70 & & & & & \\
\hline & & & 6 & 80 & & & & & \\
\hline & & & 8 & 90 & & & & & \\
\hline & & & 10 & 100 & & & & & \\
\hline & & & 12 & 100 & & & & & \\
\hline & 4th & 1 & 2 & 20 & $\begin{array}{c}y= \\
0.32+6.89 x\end{array}$ & $\begin{array}{c}4.67 \\
(3.6-5.74)\end{array}$ & $\begin{array}{c}8 \\
(3.6-5.74)\end{array}$ & $\begin{array}{c}1258 \\
(11.46-13.7)\end{array}$ & 48.80 \\
\hline & & & 4 & 40 & & & & & \\
\hline & & & 6 & 65 & & & & & \\
\hline & & & 8 & 90 & & & & & \\
\hline & & & 10 & 95 & & & & & \\
\hline & & & 12 & 95 & & & & & \\
\hline
\end{tabular}




\begin{tabular}{|c|c|c|c|c|c|c|c|c|c|}
\hline \multirow[t]{24}{*}{ An. stephensi } & $1 \mathrm{st}$ & 24 & 2 & 100 & $\mathrm{a}$ & $\mathrm{a}$ & $\mathrm{a}$ & $\mathrm{a}$ & $\mathrm{a}$ \\
\hline & & & 4 & 100 & & & & & \\
\hline & & & 6 & 100 & & & & & \\
\hline & & & 8 & 100 & & & & & \\
\hline & & & 10 & 100 & & & & & \\
\hline & & & 12 & 100 & & & & & \\
\hline & 2nd & 24 & 2 & 10 & a & a & $\mathrm{a}$ & $\mathrm{a}$ & $\mathrm{a}$ \\
\hline & & & 4 & 50 & & & & & \\
\hline & & & 6 & 65 & & & & & \\
\hline & & & 8 & 90 & & & & & \\
\hline & & & 10 & 95 & & & & & \\
\hline & & & 12 & 100 & & & & & \\
\hline & 3rd & 24 & 2 & 75 & $\begin{array}{c}y= \\
0.66+7.21 x\end{array}$ & $\begin{array}{c}1.58 \\
(0.41-2.75)\end{array}$ & $\begin{array}{c}8.91 \\
(7.87-9.95)\end{array}$ & $\begin{array}{c}12.30 \\
(11.18-13.42)\end{array}$ & 56.10 \\
\hline & & & 4 & 80 & & & & & \\
\hline & & & 6 & 85 & & & & & \\
\hline & & & 8 & 90 & & & & & \\
\hline & & & 10 & 90 & & & & & \\
\hline & & & 12 & 95 & & & & & \\
\hline & 4th & 24 & 2 & 50 & $\begin{array}{c}y= \\
0.48+6.61 x\end{array}$ & $\begin{array}{c}2 \\
(0.83-3.17)\end{array}$ & $\begin{array}{c}12 \\
(10.88-13.12)\end{array}$ & $\begin{array}{c}13.18 \\
(12.04-14.32)\end{array}$ & 46.70 \\
\hline & & & 4 & 60 & & & & & \\
\hline & & & 6 & 65 & & & & & \\
\hline & & & 8 & 70 & & & & & \\
\hline & & & 10 & 85 & & & & & \\
\hline & & & 12 & 90 & & & & & \\
\hline
\end{tabular}

a, $100 \%$ mortality; b, no mortality.

Table 2. Pupicidal efficacies of AgNPs synthesized by using the A. niger against the Ae. aegypti, Cx. quinquefasciatus and An. stephensi.

\begin{tabular}{|c|c|c|c|c|c|c|c|c|}
\hline Species & $\begin{array}{l}\text { Exposure } \\
\text { time (hrs) }\end{array}$ & $\begin{array}{l}\text { Concentrations } \\
\text { (ppm) }\end{array}$ & $\begin{array}{c}\% \\
\text { mortality }\end{array}$ & $\begin{array}{l}\text { Probit } \\
\text { equations }\end{array}$ & $\mathrm{LC}_{50}$ & $\mathrm{LC}_{90}$ & $\mathrm{LC}_{99}$ & $x^{2}$ \\
\hline \multirow[t]{6}{*}{ Ae. aegypti } & \multirow[t]{6}{*}{2} & 2 & 45 & \multirow[t]{6}{*}{$\begin{array}{c}y= \\
0.44+6.51 x\end{array}$} & \multirow[t]{6}{*}{$\begin{array}{c}4 \\
(2.77-5.23)\end{array}$} & \multirow[t]{6}{*}{$\begin{array}{c}12 \\
(11.77-13.23)\end{array}$} & \multirow[t]{6}{*}{$\begin{array}{c}14 \\
(12.77-15.23)\end{array}$} & \multirow[t]{6}{*}{44.48} \\
\hline & & 4 & 50 & & & & & \\
\hline & & 6 & 55 & & & & & \\
\hline & & 8 & 70 & & & & & \\
\hline & & 10 & 80 & & & & & \\
\hline & & 12 & 90 & & & & & \\
\hline \multirow[t]{6}{*}{$\begin{array}{c}C x . \\
\text { quinquefascitus }\end{array}$} & \multirow[t]{6}{*}{20} & 2 & 40 & \multirow[t]{6}{*}{$\begin{array}{c}y= \\
0.40+6.25 x\end{array}$} & \multirow[t]{6}{*}{$\begin{array}{c}6 \\
(4.77-6.23)\end{array}$} & \multirow[t]{6}{*}{$\begin{array}{c}14 \\
(12.77-15.23)\end{array}$} & \multirow[t]{6}{*}{$\begin{array}{c}17 \\
(15.17-17.23)\end{array}$} & \multirow[t]{6}{*}{42.40} \\
\hline & & 4 & 45 & & & & & \\
\hline & & 6 & 50 & & & & & \\
\hline & & 8 & 65 & & & & & \\
\hline & & 10 & 70 & & & & & \\
\hline & & 12 & 80 & & & & & \\
\hline \multirow[t]{6}{*}{ An. stephensi } & \multirow[t]{6}{*}{24} & 2 & 00 & \multirow[t]{6}{*}{$\mathrm{b}$} & \multirow[t]{6}{*}{$\mathrm{b}$} & \multirow[t]{6}{*}{$\mathrm{b}$} & \multirow[t]{6}{*}{$\mathrm{b}$} & \multirow[t]{6}{*}{$\mathrm{b}$} \\
\hline & & 4 & 00 & & & & & \\
\hline & & 6 & 00 & & & & & \\
\hline & & 8 & 00 & & & & & \\
\hline & & 10 & 00 & & & & & \\
\hline & & 12 & 00 & & & & & \\
\hline
\end{tabular}

b, no mortality. 


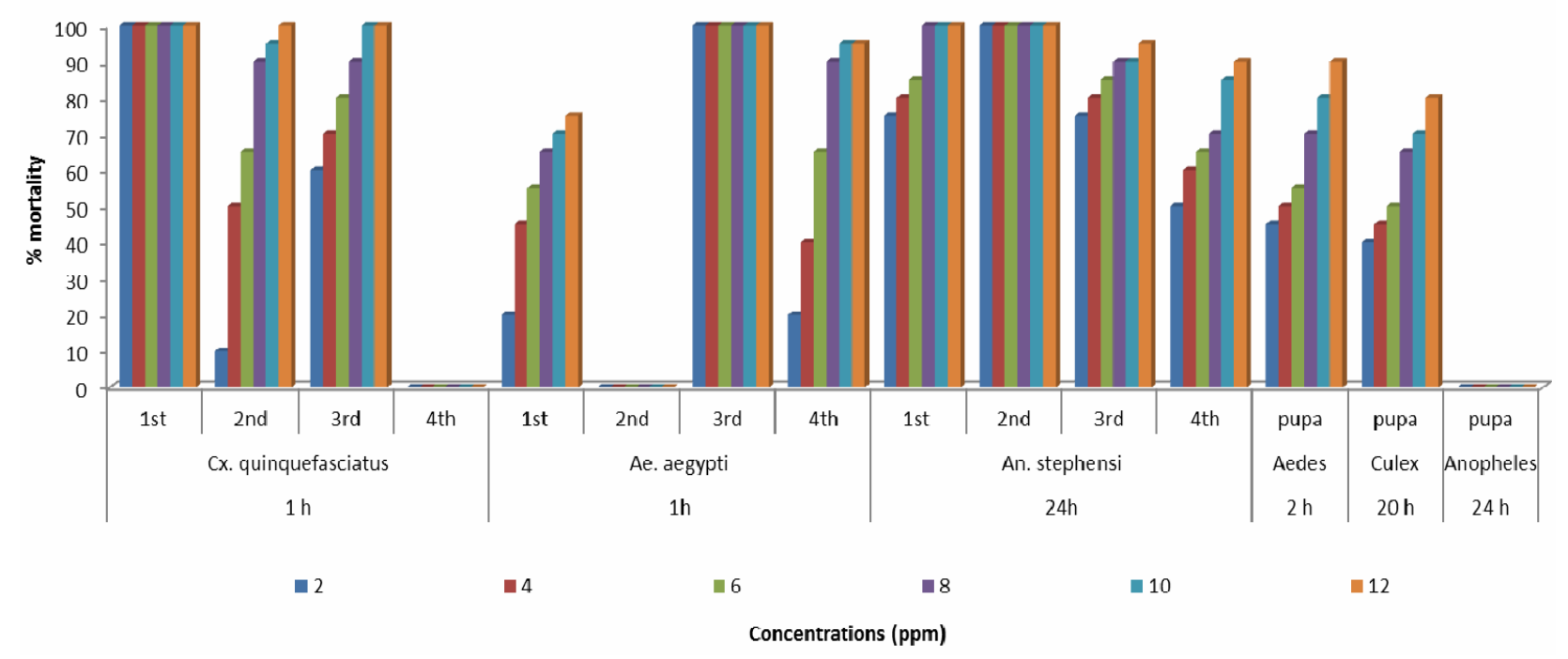

Figure 2. Relationship between the \% mortality and concentrations of AgNPs synthesized by A. niger against the larvae and pupae of $C x$. quinquefasciatus, Ae. aegypti and An. stephensi after different hours of exposure.

stage of An. stephensi (Figure 2).

The pupae of Ae. aegypti were found highly susceptible to the A. niger synthesized AgNPs than the pupae of $C x$. quinquefasciatus and An. stephensi. The mortality was scored after different hours of exposure. The efficacy for the pupae of Ae. aegypti $\left(\mathrm{LC}_{50} 4, \mathrm{LC}_{90} 12, \mathrm{LC}_{99}\right.$ $14 \mathrm{ppm}$ ) after $2 \mathrm{~h}$, for $C x$. quinquefasciatus $\left(\mathrm{LC}_{50} 6, \mathrm{LC}_{90}\right.$ 14, LC $9917 \mathrm{ppm}$ ) after $20 \mathrm{~h}$ were observed with their probit equations and confidential limits and no mortality could be observed for the pupae of An. stephensi after 24 h (Table 2). The chi-square values calculated at $4 \mathrm{df}$ were 44.84 and 42.40 for pupae of Ae. aegypti and $C x$. quinquefasciatus. These chi-square values for pupae of Ae. aegypti and $C x$. quinquefasciatus were higher than the critical value of chi-square at significance level. The relationship between the concentrations and \% mortality were shown for pupae of Ae. aegypti, Cx. quinquefasciatus and An. stephensi (Figure 2).

\section{Discussion}

AgNPs synthesized by using the soil fungus $A$. niger 2587 possessed higher larvicidal and pupicidal efficacy against Cx. quinquefasciatus, Ae. aegypti and An. stephensi in the present study. The production of AgNPs synthesized by using the soil fungus $A$. niger 2587 was evaluated through the UV-vis spectrophotometer in a range of wavelength from $350-850 \mathrm{~nm}$. This revealed a peak at $480 \mathrm{~nm}$ in the fungal liquid component of soil fungus A. niger 2587 indicating the productions of AgNPs. The result was similar to the previous study [24].

The larvicidal activity of silver nanoparticles synthesized by $N$. nucifera leaf extract has been evaluated against the malaria and filariasis vectors [25]. All ex- tracts showed moderate larvicidal effects; however, the maximum efficacy was observed in crude methanol, aqueous, and synthesized silver nanoparticles against the larvae of An. subpictus ( $\mathrm{LC}_{50} 8.89,11.82$, and $0.69 \mathrm{ppm}$, $\mathrm{LC}_{90} 28.65,36.06$, and $2.15 \mathrm{ppm}$ ) and against the larvae of $C x$. quinquefasciatus ( $\mathrm{LC}_{50} 9.51,13.65$ and $1.10 \mathrm{ppm}$, $\mathrm{LC}_{90}$ 28.13, 35.83 and $3.59 \mathrm{ppm}$ ), respectively. The antiparasitic activity efficacies of synthesized AgNPs using the aqueous leaf extract of $M$. pudica against the larvae of malaria vector An. subpictus, filariasis vector $C x$. quinquefasciatus and $R$. microplus have been determined [26]. The maximum efficacy was observed in synthesized AgNPs against the larvae of An. subpictus, $C x$. quinquefasciatus and $R$. microplus $\left(\mathrm{LC}_{50}\right.$ 13.90, 11.73 and $8.98 \mathrm{mg} / \mathrm{L}$ and $\mathrm{r}^{2}=0.411,0.286$ and 0.479 ), respectively. The larvicidal activity of synthesized AgNPs utilizing aqueous extract from $E$. prostrate, a member of the Asteracae, has been investigated against fourth instar larvae of filariasis vector, $C x$. quinquefasciatus and malaria vector, An. subpictus [27]. The maximum efficacy was observed in the crude aqueous and synthesized AgNPs against $C x$. quinquefasciatus ( $\mathrm{LC}_{50} 27.49$ and $4.56 \mathrm{mg} / \mathrm{L} ; \mathrm{LC}_{90} 70.38$ and $13.14 \mathrm{mg} / \mathrm{L}$ ) and against $A n$. subpictus ( $\mathrm{LC}_{50} 27.85$ and $5.14 \mathrm{mg} / \mathrm{L} ; \mathrm{LC}_{90} 71.45$ and $25.68 \mathrm{mg} / \mathrm{L}$ ), respectively. A biological method has been used to synthesize stable silver nanoparticles that were tested as mosquito larvicides against An. stephensi, Ae. aegypti and $C x$. quinquefasciatus [28]. The median $\mathrm{LC}_{50}$ of silver nanoparticles that killed fourth instars of $A e$. aegypti, Cx. quinquefasciatus and An. stephensi were 0.30, 0.41 and $2.12 \mathrm{ppm}$, respectively. The biolarvicidal and pupicidal activity of silver nanoparticles synthesized using E. hitra plant leaf extract against malaria vector $A n$. 
stephensi has been determined [29]. They found that the synthesized AgNPs were highly toxic than the methnolic crude extract against malaria vector. The larvicidal activity of silver nanoparticles synthesized using $P$. daemia plant latex against Ae. aegypti, An. stephensi and nontarget fish $P$. reticulate has been evaluated [30]. The larvicidal activities to determine the efficacies of synthesized silver nanoparticles (AgNPs) using aqueous leaf extract of $V$. rosea against the larvae of malaria vector $A n$. stephensi Liston and filariasis vector $C x$. quinquefasciatus Say (Diptera: Culicidae) has been evaluated [31]. These results were based on plant mediated silver nanoparticles and have been tested against the larvae of mosquito and non-target organisms also, while, in the present study the AgNPs were synthesized by using the soil fungus and have also been tested against the larvae and pupae of mosquito.

\section{Conclusion}

The AgNPs synthesized by using the soil fungi A. niger has been tested against the larvae and pupae of $C x$. quinquefasciatus, Ae. aegypti and An. stephensi. By this approach, it is suggestive that this rapid synthesis of nanoparticles would be proper for developing a biological process for mosquito control.

\section{Acknowledgements}

We sincerely thank to acknowledge Prof P. S. Satsangi Sahab, Chairman, of Advisory Committee on Education, Dayalbagh Educational Institute. Prof. V. G. Das, Director, Dayalbagh Educational Institute for providing support and encouragements for the work. We also thank to UGC, New Delhi, Major Research Project (39-599/2010) for financial support. We also thank to Dr. Shashi Wadhawa for TEM (AIIMS, New Delhi).

\section{REFERENCES}

[1] World Health Organization, "WHO 10 Facts on Malaria," 2012.

http://www.who.int/features/factfiles/malaria/en/index.html

[2] World Health Organization, “Lymphatic Filariasis,” 2012. http://www.who.int/mediacentre/factsheets/fs102/en/

[3] World Health Organization, "Dengue and severe dengue," 2012. http://www.who.int/mediacentre/factsheets/fs117/en/

[4] M. C. Wirth, W. E. Walton and B. A. Federici, "Evaluation of Resistance to the Bascillus sphaericus Bin Toxin is Phenotypically Masked by Combination with the Mosquitocidal Proteins of Bascillus thuringienesis Subspecies israelensis,” Environmental Microbiology, Vol. 12, No. 5, 2010, pp. 1154-1160. doi:10.1111/j.1462-2920.2010.02156.x

[5] M. Govindrajan, A. Jebamesan and D. Reetha, "Larvici- dal Effect of Extracellular Secondary Metabolites of Different Fungi against the Mosquito, Culex quinquefasciatus Say,” Tropical Biomedicine, Vol. 22, No. 1, 2005, pp. 1-3.

[6] S. Namita and P. Soam, "Effect of Chrysosporium keratinophilum Metabolites against Culex quinquefasciatus after Chromatographic Purification,” Parasitology Research, Vol. 107, No. 6, 2010, pp. 1329-1336. doi:10.1007/s00436-010-2003-y

[7] S. Prakash, S. Gavendra, S. Namita and S. Sweta, "Pathogenicity of Fusarium oxysporum against the Larvae of Culex quinquefasciatus (Say) and Anopheles stephensi (Liston) in Laboratory,” Parasitology Research, Vol. 107, No. 3, 2010, pp. 651-655. doi:10.1007/s00436-010-1911-1

[8] S. Namita and P. Soam, “Aspergillus niger Metabolites Efficacies against the Mosquito Larval (Culex quinquefasciatus, Anopheles stephensi and Aedes aegypti) Population after Column Chromatography,” American Journal of Microbiology, Vol. 2, No. 1, 2011, pp. 15-20. doi:10.3844/ajmsp.2011.15.20

[9] S. Namita and P.Soam, "Larvicidal Effect of Verticillium lecanii Metabolites on Culex quinquefasciatus and Aedes aegypti Larvae,” Asian Pacific Journal of Tropical Disease, Vol. 2, No. 3, 2012, pp. 220-224. doi:10.1016/S2222-1808(12)60050-4

[10] P. Singh and R. B. Raja, "Biological Synthesis and Characterization of Silver Nanoparticles Using the Fungus Trichoderma harzianum," Asian Journal of Experimental Biology and Science, Vol. 2, No. 4, 2011, pp. 600-605.

[11] K. Vahabi, G. A. Mansoori and S. Karimi, "Biosynthesis of Silver Nanoparticles by Fungus Trichoderma ressei," Inscience Journal, Vol. 1, No. 1, 2011, pp. 65-79. doi:10.5640/insc.010165

[12] H. B. Patil, S. V. Borse, D. R. Patil, U. K. Patil and H. M. Patil, "Synthesis of Silver Nanoparticles by Microbial Method and Their Characterization," Archives of Physics Research, Vol. 2, No. 3, 2011, pp. 153-158.

[13] G. Li, D. He, Y. Qian, B. Guan, S. Gao, Y. Cui, K. Yokoyama and L. Wang, "Fungus Mediated Green Synthesis of Silver Nanoparticles Using Aspergillus terreus," International Journal of Molecular Sciences, Vol. 13, No. 1, 2012, pp. 466-476. doi:10.3390/ijms13010466

[14] T. S. Anitha and P. Palanivelu, "Synthesis and Structural Characterization of Polydisperse Silver and Multidishaped Gold Nanoparticles Using Fusarium Oxysporum MTCC 284," Digest Journal of Nanomateials and Biostructure, Vol. 6, No. 4, 2011, pp. 1587-1595.

[15] N. Soni and S. Prakash, "Factors Affecting the Geometry of Silver Nanoparticles Synthesis in Chrysosporium tropicum and Fusarium oxysporum," American Journal of Nanotechnology, Vol. 2, No. 1, 2011, pp. 112-121.

[16] R. B. Salunkhe, S. V. Patil, C. D. Patil and B. K. Salunkhe, "Larvicidal Potential of Silver Nanoparticles Synthesized Using Fungus Cochliobolus lunatus against Aedes aegypti (Linnaeus, 1762) and Anopheles stephensi Liston (Diptera; Culicidae),” Parasitology Research, Vol. 109, No. 3, 2011, pp. 823-831. doi:10.1007/s00436-011-2328-1

[17] N. Soni and S. Prakash, "Efficacy of Fungus Mediated 
Silver and Gold Nanoparticles against Aedes aegypti Larvae,” Parasitology Research, Vol. 110, No. 1, 2012, pp. 175-184. doi:10.1007/s00436-011-2467-4

[18] N. Soni and S. Prakash, "Entomopathogenic Fungus Generated Nanoparticles for Enhancement of Efficacy in Culex quinquefasciatus and Anopheles stephensi," Asian Pacific Journal of Tropical Disease, Vol. 2, No. 2, 2012, pp. S356-S361. doi:10.1016/S2222-1808(12)60181-9

[19] N. Soni and S. Prakash, "Fungal Mediated Nano Silver: An Effective Adulticide against Mosquito,” Parasitology Research, Vol. 111, No. 5, 2012, pp. 2091-2098. doi:10.1007/s00436-012-3056-X

[20] J. M. Gardner and J. S. Pillai, "Tolypocladium cylindrosporum (Deuteromycotina: Moniliales), a Fungal Pathogen of the Mosquito Aedes australis,” Mycopatholigia, Vol. 97, No. 2, 1987, pp. 77-82. doi:10.1007/BF00436841

[21] World Health Organization, "Guidelines for Laboratory and Field Testing of Mosquito Larvicides,” 2005.

[22] D. J. Finney, "Probit Analysis,” 3rd Edition, Canbridge University Press, Cambridge, 1971.

[23] W. S. Abbott, "A Method of Computing the Effectiveness of an Insecticide," Journal of Economical Entomology, Vol. 18, No. 1, 1925, pp. 265-266.

[24] P. Mukherjee, A. Ahmad, D. Mandal, S. Senapati, S. R. Sainkar, M. I. Khan, R. Parishcha, P. V. Ajaykumar, M. Alam, R. Kumar and M. Sastry, "Fungus-Mediated Synthesis of Silver Nanoparticles and Their Immobilization in the Mycelia Matrix: A Novel Biological Approach to Nanoparticle Synthesis,” Nano Letters, Vol. 1, No. 10, 2001, pp. 515-519. doi:10.1021/nl0155274

[25] T. Santhoshkumar, A. A. Rahuman, G. Rajakumar, S. Marimuthu, A. Bagavan, C. Jayaseelan, A. A. Zahir, G. Elango and C. Kamaraj, "Synthesis of Silver Nanoparticles Using Nelumbo nucifera Leaf Extract and Its Larvicidal Activity against Malaria and Filariasis Vectors," Parasitology Research, Vol. 108, No. 3, 2011, pp. 693-702. doi:10.1007/s00436-010-2115-4
[26] S. Marimuthu, A. A. Rahuman, G. Rajakumar, T. Santhoshkumar, A. V. Kirthi, C. Jayaseelan, A. Bagavan, A. A. Zahir, G. Elango and C. Kamaraj, "Evaluation of Green Synthesized Green Silver Nanoparticles against Parasites,” Parasitology Research, Vol. 108, No. 6, 2011, pp. 1541-1549. doi:10.1007/s00436-010-2212-4

[27] G. Rajkumar and A. A. Rahuman, "Larvicidal Activity of Synthesized Silver Nanoparticles Using Eclipta prostrata Leaf Extract against Filariasis and Malaria Vector,” Acta Tropica, Vol. 118, No. 3, 2011, pp. 196-203. doi:10.1016/j.actatropica.2011.03.003

[28] N. K. Arjunan, K. Murugan, C. Rejeeth, P. Madhiyazhagan and R. Donald, "Green Synthesis of Silver Nanoparticles for the Control of Mosquito Vectors of Malaria, Filariasis and Dengue," Vector Borne and Zoonotic Diseases, Vol. 12, No. 3, 2012, pp. 262-268. doi:10.1089/vbz.2011.0661

[29] K. A. Priyadarshini, K. Murugan, C. Panneerselvam, S. Ponarulselvam, J. S. Hwang and M. Nicoletti, "Biolarvicidal and Pupicidal Potential of Silver Nanoparticles Synthesized Using Euphorbia hitra against Anopheles stephensi Liston (Diptera: Culicidae)," Parasitology Research, Vol. 111, No. 3, 2012, pp. 997-1006. doi:10.1007/s00436-012-2924-8

[30] C. D. Patil, H. P. Borase, S. V. Patil, R. B. Salunkhe and B. K. Salunkhe, "Larvicidal Activity of Silver Nanoparticles Synthesized Using Pergularia daemia Plant Latex against Aedes aegypti and Anopheles stephensi and NonTarget Fish Poicillia reticulate," Parasitology Research, Vol. 111, No. 2, 2012, pp. 555-562. doi:10.1007/s00436-012-2867-0

[31] Subarani, S. Sabhanayakam and C. Kamaraj, "Studies on the Impact of Biosynthesized Silver Nanoparticles (AgNPs) in Relation to Malaria and Filariasis Vector Control against Anopheles stephensi Liston and Culex quinquefasciatus Say (Diptera: Culicidae),” Parasitology Research, Vol. 112, No. 2, 2012, pp. 487-499. doi:10.1007/s00436-012-3158-5 